\title{
Observation and Analysis of Self-Amplified Spontaneous Emission at the APS Low- Energy Undulator Test Line
}

N.D. Arnold, J. Attig, G. Banks, R. Bechtold, K. Beczek, C. Benson, S. Berg, W. Berg, S.G. Biedron, J.A Biggs, M. Borland, K. Boerste, M. Bosek, W.R. Brzowski, J. Budz, J.A. Carwardine, P. Castro", Y.-C. Chae, S. Christensen, C. Clark, M. Conde ${ }^{\S}$, E.A. Crosbie, G.A. Decker, R.J. Dejus, H. DeLeon, P.K. Den Hartog, B.N. Deriy, D. Dohan, P. Dombrowski, D. Donkers, C.L. Doose, R.J. Dortwegt, G.A. Edwards, Y. Eidelman, M.J. Erdmann, J. Error, R. Ferry, R. Flood, J. Forrestal, H. Freund ${ }^{+}$, H. Friedsam, J. Gagliano, W. Gai ${ }^{\S}$, J.N. Galayda, R. Gerig, R.L. Gilmore, E. Gluskin, G.A. Goeppner, J. Goetzen, C. Gold, A.J. Gorski, A.E. Grelick, M.W. Hahne, S. Hanuska, K.C. Harkay, G. Harris, A.L. Hillman, R. Hogrefe, J. Hoyt, Z. Huang, J.M. Jagger, W.G. Jansma, M. Jaski, S.J. Jones, R.T. Keane, A.L. Kelly, C. Keyser, K.-J. Kim, S.H. Kim, M. Kirshenbaum, J.H. Klick, K. Knoerzer, R.J. Koldenhoven, M. Knott, S. Labuda, R. Laird, J. Lang, F. Lenkszus, E.S. Lessner, J.W. Lewellen, Y. Li, R.M. Lill, A.H. Lumpkin, O.A. Makarov, G.M. Markovich, M. McDowell, W.P. McDowell, P.E. McNamara, T. Meier, D. Meyer, W. Michalek, S.V. Milton*, H. Moe, E.R. Moog, L. Morrison, A. Nassiri, J.R. Noonan, R. Otto, J. Pace, S.J. Pasky, J.M. Penicka, A.F. Pietryla,

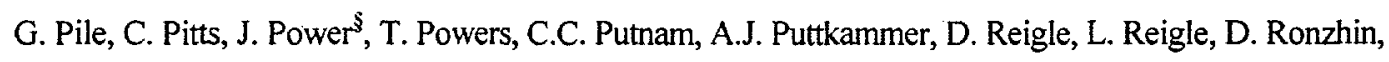
E.R. Rotela, E.F. Russell, V. Sajaev, S. Sarkar, J.C. Scapino, K. Schroeder, R.A. Seglem, N.S. Sereno, S.K. Sharma, J.F. Sidarous, O. Singh, T.L. Smith, R. Soliday, G.A. Sprau, S.J. Stein, B. Stejskal, V. Svirtun, L.C. Teng, E. Theres, K. Thompson, B.J. Tieman, J.A. Torres, E.M. Trakhtenberg, G. Travish, G.F. Trento, J. Vacca, I.B. Vasserman, N.A. Vinokurov ${ }^{\dagger}$, D.R. Walters, J. Wang, X.J. Wang ${ }^{\ddagger}$, J. Warren, S. Wesling, D.L. Weyer, G. Wiemerslage, K. Wilhelmi, R. Wright, D. Wyncott, S. Xu, B.-X. Yang, W. Yoder, R.B. Zabel

Advanced Photon Source, Argonne National Laboratory, Argonne, IL 60439, USA

${ }^{\S}$ Argonne Wakefield Accelerator, Argonne National Laboratory, Argonne, IL 60439, USA

${ }^{\ddagger}$ Brookhaven National Laboratory, Upton, NY 11973, USA

${ }^{\dagger}$ Budker Institute of Nuclear Physics, 630090 Novosibirsk, Russian Federation

"Deutsches Elektronen-Synchrotron DESY, Notkestrasse 85, 22603 Hamburg, Germany

+Science Applications International Corporation, 1710 Goodridge Drive, McLean, VA 22102, USA

* Corresponding author, milton@aps.anl.gov

The submitted manuscript has been created by the University of Chicago as Operator of Argonne National Laboratory ("Argonne") under Contract No. W-31-109-ENG-38 with the U.S. Department of Energy. The U.S. Government retains tor itself, and others acting on its behalf. a jaid-up. nonexclusive. irrevocable worldwide license in said article to reproduce. prepare derivative works. dis. tribute copies to the public. and perform publicty and display publicly. by or on behalf of the Government. 


\section{DISCLAIMER}

This report was prepared as an account of work sponsored by an agency of the United States Government. Neither the United States Government nor any agency thereof, nor any of their employees, make any warranty, express or implied, or assumes any legal liability or responsibility for the accuracy, completeness, or usefulness of any information, apparatus, product, or process disclosed, or represents that its use would not infringe privately owned rights. Reference herein to any specific commercial product, process, or service by trade name, trademark, manufacturer, or otherwise does not necessarily constitute or imply its endorsement, recommendation, or favoring by the United States Government or any agency thereof. The views and opinions of authors expressed herein do not necessarily state or reflect those of the United States Government or any agency thereof. 


\section{DISCLAIMER}

Portions of this document may be illegible in electronic image products. Images are produced from the best available original document. 


\section{Abstract}

Exponential growth of self-amplified spontaneous emission (SASE) at $530 \mathrm{~nm}$ was first experimentally observed at the Advanced Photon Source (APS) low-energy undulator test line (LEUTL) in December 1999. Since then further detailed measurements and analysis of the results have been made. Here we present the measurements and compare these with calculations based on measured electron beam properties and theoretical expectations.

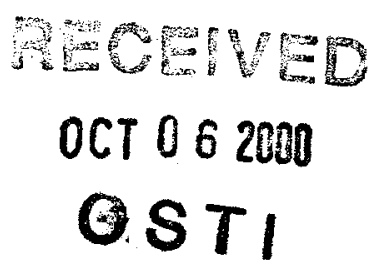




\section{Introduction}

Third-generation synchrotron-light sources such as the Advanced Photon Source (APS) at Argonne National Laboratory currently provide high-brightness $x$-ray beams to a wide range of users. These sources rely on the spontaneous emission of synchrotron radiation generated by electron bunches passing through undulator magnets. Due to the incoherent nature of the emission process between individual electrons, the intensity of the generated light is proportional to the total number of particles within the bunch. This situation can be improved dramatically by forcing the electrons to emit coherently. In such a case, the intensity is proportional to the square of the total number of coherently radiating electrons. This is the underlying essence of current thought when speaking of the "next" or "fourth-generation" of synchrotron radiation sources.

Present plans for fourth-generation synchrotron radiation facilities capitalize on the self-amplified spontaneous emission (SASE) process [1,2] to induce the required microbunching within the electron bunch needed for coherent emission. The advantage of this process is that it does not require mirrors or an input seed, but starts up naturally from spontaneous noise. The process is thus scalable to $\mathrm{x}$-ray wavelengths.

Until recently, SASE had only been observed at $633-\mathrm{nm}$ and longer wavelengths [3-6]. The requirements on the electron beam properties become increasingly stringent as the wavelength is reduced; however, significant progress has been made in electron beam production technology and beam control such that the attainment of SASE into the vacuum ultraviolet (VUV) and perhaps soft $\mathrm{x}$-ray wavelength range is becoming feasible. Progress in the study of SASE at these wavelengths will be used to guide the design of $x$-ray facilities utilizing the SASE effect [7-9]. We report here on recent progress in the study of SASE at $530 \mathrm{~nm}$ using the Low-Energy Undulator Test Line (LEUTL) facility at the APS, and briefly describe our future plans with the system. 


\section{LEUTL Description}

\subsection{Overview}

The APS linac and LEUTL systems have been configured as a test bed for SASE research and development at wavelengths ranging from the visible into the VUV. Upgrades to the linac have included the addition of radiofrequency ( $\mathrm{rf}$ ) electron guns for high-brightness electron beam generation, improvements in the magnetic lattice structure, and performance upgrades of the if modulators, low-level if systems, and some power supplies [10]. The LEUTL is a 50-m tunnel in line with the linac and is capable of housing undulators or strings of undulators of over 30 meters in length. The APS LEUTL system is designed to test concepts critical to the success of a linac-based fourth-generation light source, such as the proposed x-ray Linac Coherent Light Source (LCLS) at SLAC [9] and the TESLA-FEL at DESY [8], but at much longer wavelengths. Figure 1 shows a schematic of the LEUTL SASE system and Table 1 lists the parameters for the first three phases of the operation.

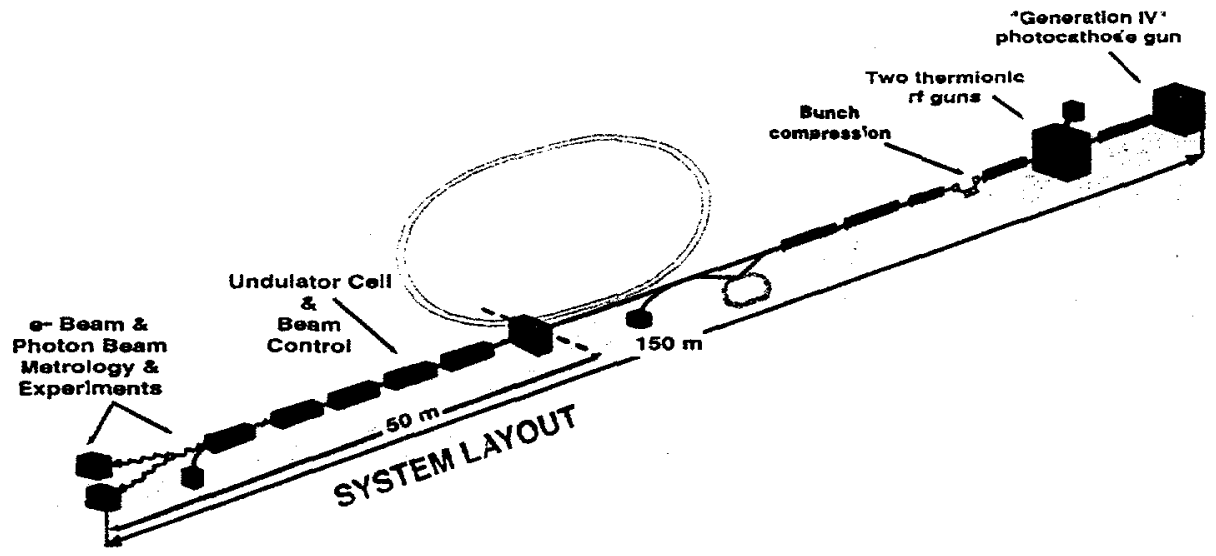

Figure 1: Schematic of the APS LEUTL system. 
Table 1: LEUTL SASE design parameters for various phases of operation.

\begin{tabular}{|l|c|c|c|}
\hline & Phase 1 & Phase 2 & Phase 3 \\
\hline Wavelength [nm] & 530 & 120 & 59 \\
\hline Electron Energy [MeV] & 217 & 457 & 650 \\
\hline Normalized rms Emittance $[\boldsymbol{\mu m}]$ & 5 & 3 & 3 \\
\hline Energy Spread rms [\%] & 0.1 & 0.1 & 0.1 \\
\hline Peak Current [A] & 100 & 300 & 500 \\
\hline Undulator Period [cm] & & 3.3 & \\
\hline Magnetic Field [T] & & 1.0 & \\
\hline Undulator Gap [mm] & & 9.3 & 2.4 \\
\hline Length of One Undulator $[\mathrm{m}]$ & & 0.72 & 0.77 \\
\hline Power Gain Length [m] & 0.81 & $9 \times 2.4$ & $9 \times 2.4$ \\
\hline Installed Undulator Length $[\mathrm{m}]$ & $5 \times 2.4$ then $9 \times 2.4$ & \multicolumn{3}{|l}{} \\
\hline
\end{tabular}

\subsection{Parameters}

We have chosen to concentrate our initial efforts on investigation of SASE at $530 \mathrm{~nm}$. Optics and optical diagnostics at this wavelength are readily available, the required electron beam performance at $217 \mathrm{MeV}$ is readily achievable, and it is well within the operating envelope of the APS linac. As performance is improved, the energy of the electron beam will be increased to explore SASE at shorter wavelengths (see Table 1).

\subsection{Linac}

A schematic of the APS linac is shown in Figure 2. It consists of thirteen S-band, 3-m-long, constant gradient, travelling wave accelerating structures similar to the SLAC design. Three 35-MW klystrons each power four $3-\mathrm{m}$ accelerating structures through a SLED. A photocathode gun (PCgun) is powered by a single 35-MW klystron, while either of two thermionic rf guns share power with a single accelerating structure that follows the photocathode if gun. Power distribution to these rf guns and linac structure is through S-band If switches. In the PCgun mode, the electron beam can 
be accelerated by all thirteen structures. The maximum energy attainable in PCgun mode is 650 $\mathrm{MeV}$. One accelerating structure, the first, is not used to accelerate beam in the thermionic if gun configuration.

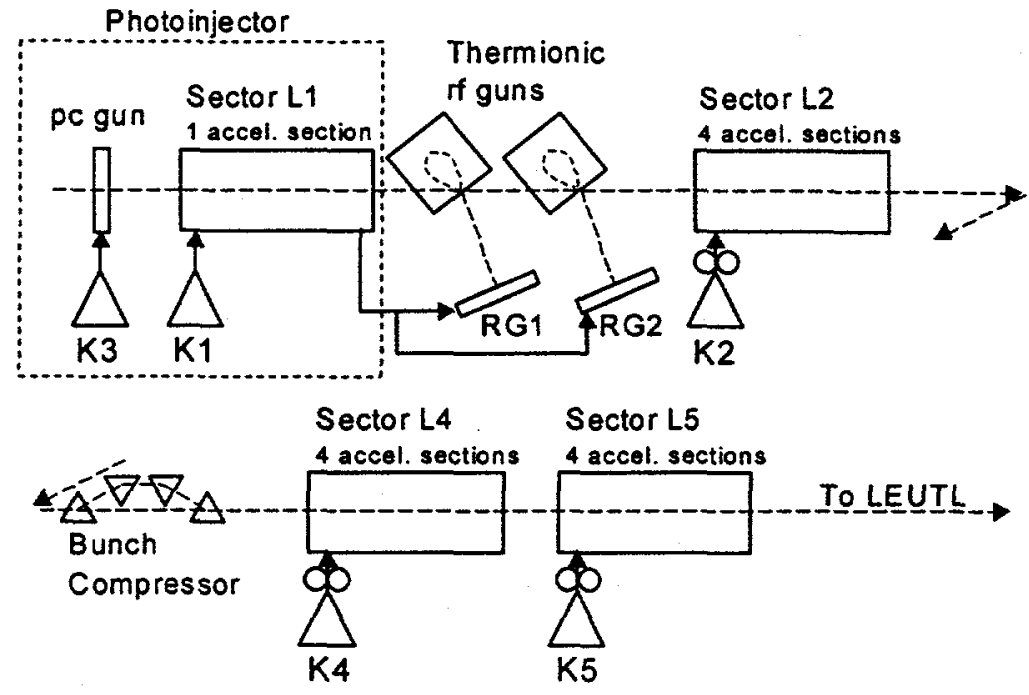

Figure 2: Schematic of the APS linac system.

A bunch compression system has recently been installed and commissioned within the linac following the fifth accelerating structure [11,12]. It will provide higher peak currents for both photocathode and thermionic if guns. It was, however, not installed during the measurements reported here.

\section{Guns}

High-brightness electron bunches are generated using either a photocathode rf gun system or a thermionic of gun with alpha-magnet compression. The photocathode if gun is a 1.6-cell Brookhaven S-band gun IV model $[6,13]$ that employs a copper photocathode. A Nd:glass picosecond drive laser system is used to generate the electrons [14]. It is assembled from commercially available components and is timing stabilized to the if within 1 picosecond. This system can generate a single electron bunch of roughly $1 \mathrm{nC}$ at a $6-\mathrm{Hz}$ repetition rate. The thermionic of gun is a $1-1 / 2$ cell S-band gun with a tungsten dispenser cathode. An alpha magnet is 
used to both inject beam into the APS linac and to compress the bunch to very high peak currents. An 8-ns pulsed kicker magnet is used for safety purposes to limit the total charge delivered to the linac. The result is a bunch train of roughly 23 bunches, each with approximately $48 \mathrm{pC}$ of charge. This thermionic rf gun system is extremely reliable and is used as the primary injector for the APS storage ring.

\subsection{Undulators}

The undulator system is built of identical cells. Each cell contains a fixed-gap 2.4-m-long undulator with a $3.3-\mathrm{cm}$ period and an undulator parameter, $\mathrm{K}$, of 3.1 . There is a diagnostic station, a horizontal focusing quadrupole, and horizontal and vertical steering before the first undulator, between each of the currently installed five undulators, and after the final undulator. The longitudinal spacing between undulators, about $0.32 \mathrm{~m}$, is set to insure proper phase matching of the optical fields and the electron beam at successive undulator sections. In its current configuration of five cells, the total installed undulator magnetic length is 12 meters.

\subsection{Diagnostic Arrangement}

Direct measurement of the exponential growth of the optical intensity as a function of length along the undulator is a hallmark of our diagnostics design. Figure 3 is a representative diagram of the diagnostics station located between each undulator. Electron beam diagnostics include YAG and optical transition radiation (OTR) screens viewed by a CCD camera. Two sets of filter wheels afford both intensity and, to a coarse degree, wavelength selectivity. Completing the primary electron beam diagnostics at each station are capacitive pickup beam position monitors (BPMs) with single-shot resolution of less than $10 \mu \mathrm{m}$ for bunch charges of $1 \mathrm{nC}$. 


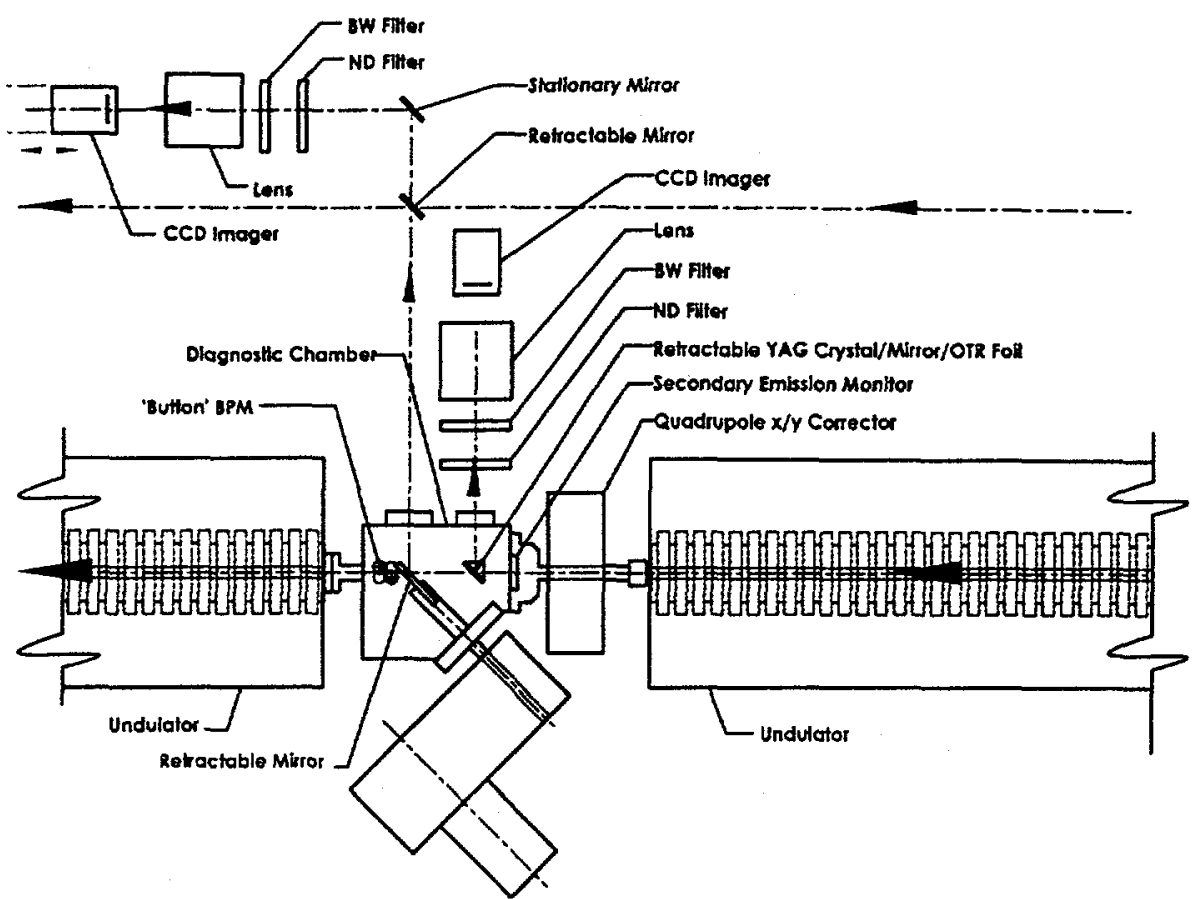

Figure 3: Schematic of the undulator diagnostic stations.

In-tunnel visible light detectors (VLDs) consist of three-position actuators with positions as follows: 1) out, 2) mirror, 3) mirror with $600-\mu \mathrm{m}$ diameter hole. These are used to deflect the synchrotron light through a set of filters to a CCD camera. All five mirror hole centers have been aligned along the beamline to within $20 \mu \mathrm{m}$ of the ideal electron beam trajectory. The cameras viewing these mirrors can be focused at the mirror, at infinity, or at any distance between the two. Focus at infinity is valuable as it allows us to measure the angular distribution of the optical radiation.

A green alignment laser is located at the entrance to the undulator string. It is used to insure that all mirrors and optical components are properly aligned. It also serves as an intensity and wavelength calibration source for the optical systems.

Further details of the LEUTL system, the undulators, and the diagnostics arrangements can be found in the references [15-19]. 
3. Gain Analysis

\subsection{Via Fitted Intensity Growth}

Measurements of the signal intensity as a function of length along the undulator can be used to extract the SASE gain length. In the SASE FEL, the Fourier harmonics of the field amplitude $E_{\omega}(s, z)$ at frequency $\omega$ grow exponentially with position along the undulator $z$ :

$$
E_{\omega}(s, z) \propto \exp (g z)
$$

where $s$ is the position along the bunch. Near the optimal frequency $\omega_{0}$ at the point $s_{0}$ within the bunch, where the longitudinal particle density is maximal, the factor $g$ reaches a maximum, and therefore can be represented in the form

$$
g \approx \frac{1}{2 L_{G}}\left[1-a\left(\omega-\omega_{0}\right)^{2}-b\left(s-s_{o}\right)^{2}\right]
$$

where $L_{G}$ is the power gain length at the optimal frequency and peak current, and $a$ and $b$ are constants.

The radiated energy $W$ is then proportional to

$$
\left.W \propto \int_{-\infty}^{\infty} \int_{-\infty}^{\infty} E_{\omega}(s, z)\right|^{2} d s d \omega \approx \frac{L_{G}}{z} \exp \left(\frac{z}{L_{G}}\right) \frac{\pi}{\sqrt{a b}} .
$$

Thus $W$ can be written in the form

$$
W\left(A, L_{G}, z\right) \approx A \frac{L_{G}}{z} \exp \left(\frac{z}{L_{G}}\right)
$$

The quantities $L_{G}$ and $A$ can be explicitly calculated in terms of the electron bean and undulator parameters [20-25]. 


\subsection{Via Opening Angle}

An alternative, albeit rough, way of determining the gain length is by observation of the opening angle of the optical radiation. An estimate of the gain length based on the FWHM angular divergence of the SASE radiation $\theta_{S A S E}$ is

$$
L_{G} \approx 2 \lambda_{r} / \pi \theta_{S A S E}^{2}
$$

where $\lambda_{r}$ is the observed resonant wavelength.

\subsection{Intensity Fluctuations}

Intensity fluctuations of the optical signal are intrinsic to the SASE process $[26,27]$. This is due to the startup from noise developing into a number of longitudinal degrees of freedom within the resultant optical pulse. Roughly, the number of degrees of freedom is

$$
M=\frac{\pi}{2} \frac{\sigma_{l}}{\lambda_{r}} \frac{\lambda_{u}}{z}
$$

where $\sigma$ is the rms electron bunch length, $z$ is the length of the "exponential-growth" part of the undulator (the observation point along the undulator minus approximately two power gain lengths), and $\lambda_{u}$ is the undulator period. Equation (6) is valid for $M>1$. The standard deviation of the shot-toshot fluctuations is found to be equal to $1 / \sqrt{M}$.

Although one clearly observes these fluctuations, their use for precise quantitative measurement of the SASE process is hindered by a lack of precise knowledge of the beam properties. This is further exacerbated by shot-to-shot fluctuation of the electron beam properties. 


\section{Gain Measurements}

\subsection{Earty Data}

\subsubsection{Measured Gain}

First measurement of significant SASE using the PCgun was on December 22, 1999 [28]. Figure 4 shows the optical intensity following the first four undulators. The signal is the integral over all measureable angles, within a 10-nm bandwidth, and over the duration of the electron bunch. At the time of the measurement there was significant shot-to-shot fluctuation in the beam properties and trajectory. As a result, we plot the peak measured intensity, the average of the top $5 \%$ measured intensities, and the average of all measurements at each diagnostic station. All measurements were taken with the electron beam properties shown in Table 2 .

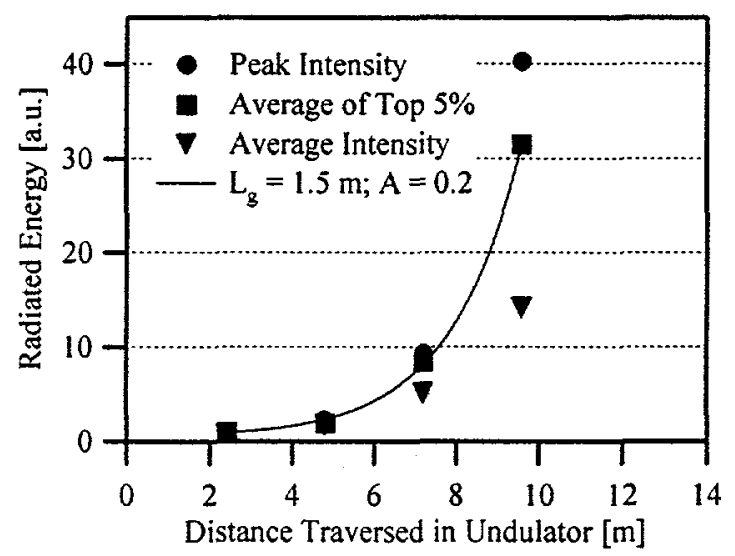

Figure 4: Early data. Radiated energy vs. distance traversed in the undulator. The PCgun source was used for this experiment. 
Table 2: Measured Linac Beam Parameters at the end of the linac using beam from the PCgun on December 22nd.

\begin{tabular}{|c|c|c|}
\hline & Typical & Min - Max \\
\hline Energy $[\mathrm{MeV}]$ & 217 & - \\
\hline Normalized Emittance $[\mu \mathrm{m}]$ & 5 & $4-8$ \\
\hline Charge/Bunch [nC] & 0.7 & $0.6-0.8$ \\
\hline Bunch Length FWHM [ps] & 5 & $4-7$ \\
\hline Energy Spread rms \% & 0.1 & $<0.1-0.2$ \\
\hline
\end{tabular}

By fitting the average of the top 5\% to the functional form given in Eq. (4), we found a gain length of $1.5 \mathrm{~m}$. Similarly, the opening angle of the SASE signal following the fourth undulator implies, from Eq. (5), a gain length of $1.6 \mathrm{~m}$.

The theoretical gain length, using the typical values listed in Table 2 and calculated by methods discussed in [20-25], is $0.7 \mathrm{~m}$. The discrepancy between theory and the experimentally measured values was probably due to incomplete knowledge of the electron beam parameters.

\subsection{Thermionic if Gun Data}

\subsubsection{Beam Properties}

Figure 5 shows SASE signal measurements as a function of length along the undulator system using beam from a high performance thermionic if gun system. Electron bunches from the thermionic if gun were optimally compressed by the alpha magnet by observing signals generated off a coherent 
transition radiation bunch length monitor [29]. Reconstruction of the longitudinal bunch profile was performed with the result tabulated in Table 3. Also shown in Table 3 are the measured electron beam properties for this experiment. Sequential measurements at each undulator diagnostics station were made for a number of electron bunches. Shown are the averages of all measurements. The intensity measured is an integration over all wavelengths, angles, and the duration of the electron bunch. With this electron source the intensity signal is also an integral over the entire 23-bunch train generated during each linac macropulse. Error bars correspond to the rms fluctuation of the measured intensity signal. Fitting to the average value of the measured signal gives a gain length of $1.1 \mathrm{~m}$.

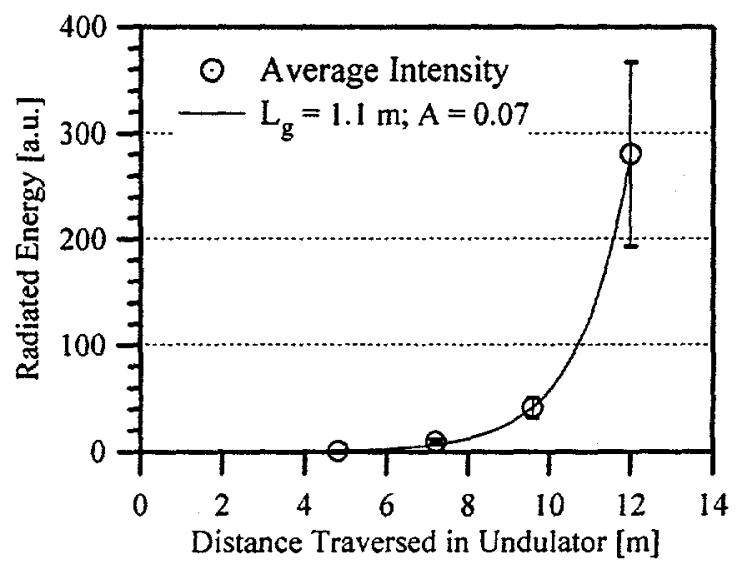

Figure 5: Radiated energy vs. distance traversed in the undulator. Thermionic rf gun source. 
Table 3: Measured Linac Beam Parameters at the end of the linac using beam from the thermionic rf gun.

\begin{tabular}{l|cc}
\hline & Typical & Min - Mox \\
\hline Energy [MeV] & 217 & - \\
Normalized Emittance [ $\mu \mathrm{m}]$ & 12 & $9-15$ \\
Charge/bunch [nC] & 0.048 & $0.043-0.052$ \\
Bunch Length FWHM [ps] & 0.35 & $0.33-0.40$ \\
Energy Spread ms \% & 0.1 & $<0.1-0.2$ \\
\hline
\end{tabular}

As before, one can calculate the expected gain lengths. Using the typical values from Table 3, a gain length of $1.0 \mathrm{~m}$ is calculated. A more complete Monte Carlo analysis using normalized three-point estimates based on the beam parameters listed in the table predicts a most probable gain length of $1.1 \mathrm{~m}$ with a distribution width of $\pm 0.2 \mathrm{~m}$, which is in good agreement with the measured data.

\subsubsection{Fluctuations}

It is interesting to note that at $530 \mathrm{~nm}$, the FWHM length of the thermionic gun electron bunch corresponds to roughly 200 optical periods and the undulator is 360 periods long. The bunch length is then less than the slippage length and equation 6 is not valid. $M$ can ,therefore, be assumed to be close to 1 . Given that each measurement is an average over the 23 bunches in the bunch train we would expect fluctuations in the intensity of $1 / \sqrt{23} \approx 20 \%$. Our data indicate fluctuations of nearly $30 \%$, indicating that fluctuations in the electron beam properties were dominant. 


\subsection{Recent PCgun Data}

\subsubsection{Measured Gain}

Figure 6 shows our most recent data taken in July 2000 using the beam from the PCgun. Also included in the figure is the fit to Eq. (4). The data points are the average of all measurements, and the error bars indicate the rms spread in the measurements. Once again the intensity is an integration over all wavelengths, angles, and the duration of the electron bunch. All data were normalized to the intensity following the second undulator. Data following the first undulator were not used in order to insure we were well into the exponential-growth regime. Data following the third undulator are missing due to problems encountered with the diagnostics system at this location.
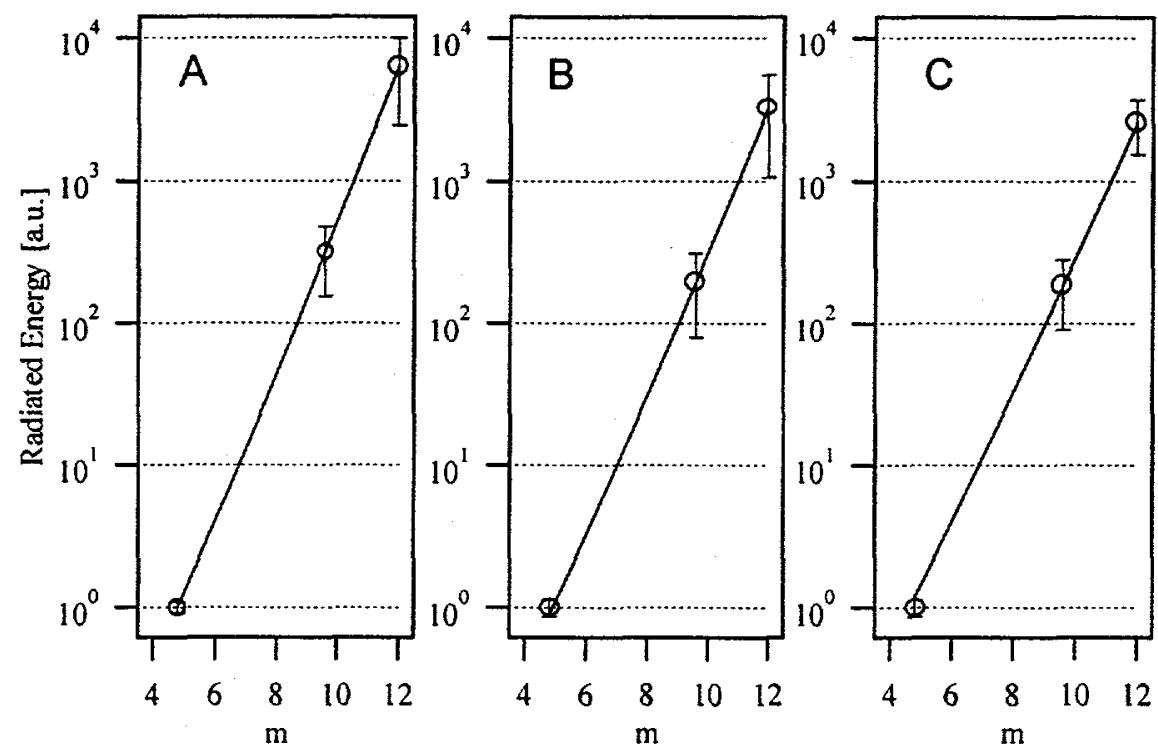

Figure 6: Radiated energy vs. distance along undulator for the three run conditions listed in Table 4.

\subsubsection{Comparison to Theory}

Table 4 lists the beam conditions for all three run conditions shown in Figure 6. Also listed are the fitted and predicted gain lengths for the listed beam conditions. The agreement is very good. The total installed length of undulator at the time of these measurements was $12 \mathrm{~m}$. For a gain length of $0.8 \mathrm{~m}$ this would imply that 15 gain lengths have been traversed. 
Table 4: Beam measurements, fitted gain length, and calculated gain lengths for the data displayed in Figure 6.

\begin{tabular}{lccc}
\hline & A & B & C \\
\hline Peak Current [A] & 170 & 130 & 150 \\
Charge [nC] & 0.42 & 0.45 & 0.50 \\
Norm. Emittance [ $\pi$ mm-mrad] & 9 & 7.5 & 7.5 \\
Fitted Gain Length [m] & 0.75 & 0.80 & 0.82 \\
Calculated Gain Length [m] & 0.77 & 0.83 & 0.76 \\
\hline
\end{tabular}

Note: rms energy spread $\sim 0.1 \%$ for all cases

Further confirmation of the gain length comes from measurement of the opening angle. We measured a FWHM opening angle following the fourth undulator of approximately $600 \mu \mathrm{rad}$, in agreement with the angular divergence of the fundamental guided mode obtained by solving the eigenmode equation [23]. From Eq. (5) this implies a gain length of $0.9 \mathrm{~m}$, again in rough agreement with the measurement of $0.8 \mathrm{~m}$.

Error bars in Figure 6 indicate the rms spread in the measured intensity. Measured spreads of the intensity signals at the last two diagnostics stations are on the order of $50 \%$ to $60 \%$. Electron bunch lengths were $300 \mu \mathrm{m} r \mathrm{~ms}$. For our parameters $M$ is calculated to be 2.4 , giving an expected fluctuation level of $64 \%$.

\subsection{Confirmation of Beam Bunching}

As further confirmation of microbunching, we observed the OTR evolution to coherent transition radiation (CTR) as a function of distance along the undulator. The synchrotron radiation signal was blocked by a thin foil immediately preceding the $45^{\circ}$ metal pickoff mirror [30]. The resultant CTR signal was then directed to the wall-mounted VLD camera system, and in the case of the fifth 
undulator it could also be transported to an optical spectrometer. A 530-nm filter was used for the VLD measurements to insure that we viewed the CTR signal at the expected bunching wavelength. Although the CTR signals as measured at the VLDs have not been fully analyzed, they do show indication of intensity gains well beyond linear. Perhaps the most significant signature of bunching, though, was via the spectrometer measurements that showed a CTR narrow-band signal at the SASE fundamental wavelength (Figure 7).

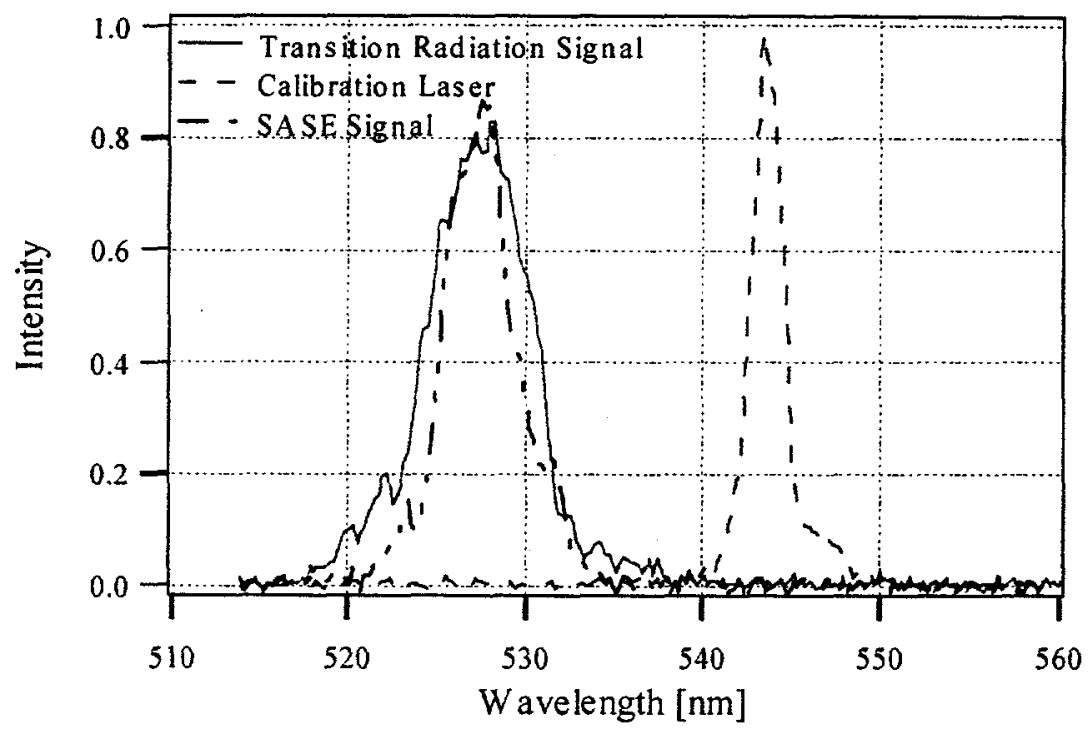

Figure 7: CTR spectrum of the microbunched beam along with the SASE spectrum at the same location. The intensities were adjusted with neutral density filters to be roughly equal. (The SASE is $\sim 200$ times brighter.) The data were not taken simultaneously. The sharp line at $543.5 \mathrm{~nm}$ is the calibration laser.

\section{Summary}

Exponential growth of the optical signal as a function of length has been directly measured at 530 $\mathrm{nm}$, providing clear evidence of the SASE process. Early measurements made using beam from the photocathode if gun indicated a gain length of $1.5 \mathrm{~m}$. This was later improved to $0.8 \mathrm{~m}$ in agreement with theory, giving a total of 15 power gain lengths within our undulator system. A thermionic if gun with alpha-magnet compression has also been used and a gain length as low as $1.1 \mathrm{~m}$ at $530 \mathrm{~nm}$ was 
measured. Initial measurements of electron beam microbunching at the resonant wavelength also provide strong evidence of the SASE process. Measurements of the gain length now agree with the theoretical predictions, but we are still suffering from fluctuations in the electron beam properties.

We have recently installed a bunch compression system into the APS linac and are in the early stages of commissioning it. Four additional undulators are also being installed, which will bring the total length of installed undulator to $21.6 \mathrm{~m}$. With this setup we will explore SASE at and beyond saturation. We will also investigate nonlinear harmonic generation [31] and increase the beam energy of the linac to begin exploration of SASE at even shorter wavelengths.

\section{Acknowledgements}

This work is supported by the U.S. Department of Energy, Office of Basic Energy Sciences, under Contract No. W-31-109-ENG-38.

\section{References:}

[1] Y.S. Derbenev, A.M. Kondratenko, and E.L. Saldin, Nucl. Instrum. Methods 193, 415 (1982).

[2] R. Bonifacio, C. Pellegrini, and L.M. Narducci, Opt. Commun. 50, 6 (1985).

[3] T.J. Orzechowski et al., Nucl. Instrum. Methods A 250, 144 (1986).

[4] D.A. Kirkpatrick et al., Phys. Fluids B 1 (7), 1511 (1989).

[5] M. Hogan et al., Phys. Rev. Lett. 81, 4807 (1998).

[6] M. Babzien et al., Phy. Rev. E 57, 6093 (1998).

[7] R. Tatchyn et al., Nucl. Instrum. Methods A 374, 274 (1996). 
[8] Conceptual Design of a $500 \mathrm{GeV} e^{+} e^{-}$Linear Collider with Integrated X-Ray Laser Facility, edited by R. Brinkmann, G. Materlik, J. Rossbach, and A. Wagner, DESY report No. DESY97-048, 1997.

[9] M. Comacchia et al., Linac Coherent Light Source (LCLS) Design Study Report, Stanford University - University of California Report No. SLAC-R-521 / UC-414, revised 1998.

[10] Travish et al.,"High-Brightness Beams from a Light Source Injector: The Advanced Photon Source Low-Energy Undulator Test Line Linac," Proceedings of the 2000 Linear Accelerator Conference, Monterey, CA, to be published.

[11] M. Borland, "Design and Performance Simulations of the Bunch Compressor for the APS LEUTL FEL," Proceedings of the 2000 Linear Accelerator Conference, Monterey, CA, to be published.

[12] M. Borland, J. Lewellen, and S. Milton, "A Highly Flexible Bunch Compressor for the APS LEUTL FEL," Proceedings of the 2000 Linear Accelerator Conference, Monterey, CA, to be published.

[13] S. Biedron et al., Proceedings of the 1999 Particle Accelerator Conference, (IEEE, New York, 1999) pp. 2024-2026.

[14] G. Travish, N. Amold, and R. Koldenhoven, Free Electron Lasers 1999, J.Feldhaus and H. Weise (Eds.), 2000 Elsevier Science B.V., II-101.

[15] S.V. Milton et al., Nucl. Instrum. Methods, A 407, 210 (1998).

[16] S.V. Milton et al., Proc. SPIE Int. Soc. Opt. Eng. 3614, 86 (1999).

[17] I.B. Vasserman et al., Proceedings of the 1999 Particle Accelerator Conference (Ref. 13), pp. 2489-2491. 
[18] I.B. Vasserman, N.A. Vinokurov, and R.J. Dejus, The $1 I^{\text {th }}$ National Conference on Synchrotron Radiation Instrumentation, Stanford, CA (to be published).

[19] E. Gluskin et al., Nucl. Instrum. Methods, A 429, 358 (1999).

[20] L.-H. Yu, S. Krinsky, and R.L. Gluckstern, Phys. Rev. Lett. 64, 3011 (1990).

[21] Y.H. Chin, K.-J. Kim, and M. Xie, Phys. Rev. A 46, 6662 (1992).

[22] M. Xie, Proceedings of the 1995 Particle Accelerator Conference, (IEEE, Dallas, 1995) pp. 183-185.

[23] M. Xie, "Exact and Variational Solutions of 3D Eigenmodes for High-Gain FELs," Nucl. Instrum. Methods A 445, 59 (2000).

[24] M. Xie, "Grand Initial Value Problem of High Gain Free Electron Lasers," these proceedings.

[25] Z. Huang and K.-J. Kim, "Solution of the Initial Value Problem for a High-Gain FEL via Van Kampen's Method," these proceedings.

[26] R. Bonifacio et al., Phys. Rev. Lett. 73, 70 (1994).

[27] E.L. Saldin, E.A. Schneidmiller, and M.V. Yurkov, DESY rep. TESLA-FEL 97-02, (1997).

[28] S.V. Milton et al., Phys. Rev. Lett. 85, 988 (2000).

[29] A. Lumpkin et al., Nucl. Instrum Methods A 429, 336 (1999).

[30] A.H. Lumpkin et al., "Utilization of CTR to Measure the Evolution of Electron-Beam Microbunching in a SASE FEL," these proceedings.

[31] H.P. Freund, S.G. Biedron, and S.V. Milton, Nucl. Instrum. Methods A 44553 (2000). 